\title{
Cell Wall Assembly in Bacillus subtilis: Visualization of Old and New Wall Material by Electron Microscopic Examination of Samples Stained Selectively for Teichoic Acid and Teichuronic Acid
}

\author{
By TAREK MERAD, ${ }^{1}$ A. RONALD ARCHIBALD, ${ }^{1}$ IAN C. HANCOCK, ${ }^{1}$ \\ COLIN R. HARWOOD ${ }^{1 *}$ AND JAN A. HOBOT ${ }^{2}$ \\ ${ }^{1}$ The Microbial Technology Group, Department of Microbiology, \\ University of Newcastle upon Tyne, Framlington Place, Newcastle upon Tyne NE2 4HH, UK \\ ${ }^{2}$ EM Unit, University of Wales College of Medicine, Heath Park, Cardiff CF4 4XN,UK
}

(Received 1 August 1988; revised 4 November 1988; accepted 15 November 1988)

\begin{abstract}
Uranyl actetate staining of thin sections allowed a distinction to be made between cell wall material that contains teichoic acid and that which contains teichuronic acid. The stain was used to study the pattern of wall assembly in Bacillus subtilis undergoing transitions between growth conditions leading to incorporation of the different anionic polymers. The results showed that new material is incorporated along the inner surface of the cylindrical region of the wall confirming, by a more direct method, results obtained earlier with teichoic acid specific phages. New material appears to be evenly distributed along the inner surface and no evidence was obtained for the presence of specific zones of incorporation.
\end{abstract}

\section{INTRODUCTION}

The mode of cell wall assembly in Bacillus subtilis was first studied by Chung et al. (1964) who concluded that growth proceeded by incorporation of new material from a narrow annular growth zone located half way along the cell. This was supported by fluorescent antibody studies of wall assembly in Bacillus licheniformis (Hughes \& Stokes, 1971). The idea that the bacterial surface expands from a single zone is in accord with the replicon hypothesis (Jacob et al., 1963) in which genome segregation is accomplished through attachment to the envelope: this intellectually attractive hypothesis has had a major influence on both the design of experiments and the interpretation of their results. Nevertheless, this idea is contradicted by an increasing body of evidence showing that wall assembly in $B$. subtilis reflects two distinguishable processes. Septa, and hence the cell poles, are formed by incorporation of new wall material from an annular growth zone but cylindrical wall is formed by the incorporation of new material at its inner surface, at many sites or in a layer, and such material is gradually pushed to the outer region of the cylinder by the continual incorporation of newer wall material during growth (Anderson et al., 1978; Mobley et al., 1984).

Evidence for an 'inside-to-outside' assembly process for cylindrical wall was obtained first in the electron microscopical study of Fan et al. (1975) who noted that bacilli that had earlier been plasmolysed subsequently deposited a densely staining layer of material at the inner wall surface and that this appeared to move through the wall during continued growth. Pooley $(1976 a, b)$ suggested that the delay observed (Mauck \& Glaser, 1972; Mauck et al., 1971) between incorporation of new material into the cell wall and its eventual appearance in the culture fluid as a degraded 'turnover' product could be explained on the basis that new material is

\footnotetext{
Abbreviations: TA, teichoic acid; TU, teichuronic acid; TA or TU walls, cell wall material containing predominantly TA or TU as the anionic polymer, respectively.
} 
incorporated at the inner surface of the wall but shed only after it has moved to the outer surface. Pulsed incorporation of radiolabelled wall material supported this interpretation: newly incorporated material was not solubilized by lytic enzymes added to a suspension of whole bacteria but was attacked by enzymes added to a suspension of isolated walls in which the inner surfaces were, of course, accessible to the lysin.

Direct evidence for the initial incorporation of new material at the inner surface of the wall was obtained by using phages and lectins to locate teichoic acid (TA), an integral wall polymer, incorporated during pulsed release of phosphate limitation in chemostat cultures of $B$. subtilis (Archibald, 1976; Anderson et al., 1978). These studies showed that the newly incorporated material was not detectable at the outer surface of the cylinder but was detected and located at the inner surface by phages specific for TA. Consideration of both the quantitative binding data and the electron microscopic distribution of phages led to the conclusion that new material was incorporated all along the inner surface of the cylinder at many sites or in a layer. This conclusion has been refuted by Schlaeppi et al. (1982) who have concluded that wall is assembled from a limited number of incorporation zones, though Mobley et al. (1984) have also concluded that incorporation proceeds at many sites. The experimental approaches used by these latter two groups, autoradiography and lectin adsorption to whole bacteria, do not give direct information on the pattern of incorporation at the inner surface. The relationship between the location of sites at which material is incorporated into the inner surface of the cell and of sites at which it becomes exposed at the cell surface may not be simple (Anderson et al., 1978), and it is therefore necessary to look directly at sites of incorporation at the inner surface in order to distinguish between multiple and few sites of incorporation.

A difficulty with the use of phages is that the maximum packing density is limited by the size of the phage heads (phage SP50 has a head diameter of $80 \mathrm{~nm}$ ) rather than by the density of receptor material in the wall; also, since even small amounts of TA can ensure phage binding (Givan et al., 1982), the technique does not discriminate between regions of the wall which have incorporated large and small amounts of new material. For example, phages might not reveal a specific growth zone if, simultaneously, material lost by turnover was replaced by sufficient material at other locations along the cylinder to permit phage binding. A further disadvantage of the technique is that phages can bind to the inner surface of the wall only after the bacteria have been disrupted. While the technique has provided the most direct and convincing evidence for the incorporation of new material along the inner surface of the wall, its disadvantages have precluded its use for a more definitive assessment of the possibility that incorporation into the inner wall surface proceeded from specific zones. In spite of the continuing experimental and theoretical attention being given to wall assembly and growth, no other direct study of the pattern of assembly at the inner wall surface has appeared since the work with phages (Archibald, 1976).

We now show that under the staining conditions used for electron microscopy, wall material that contains TA binds more uranium than does an equal weight of wall material containing a second type of anionic polymer, teichuronic acid (TU). This differential staining enables changes at the inner surface of the wall to be studied directly in bacilli undergoing transition between growth conditions resulting in incorporation of either TA or TU. The results confirm and extend earlier observations obtained with phages, and show that new wall material is inserted all along the inner surface of the cell cylinder. No evidence was found for specific zones of incorporation.

\section{METHODS}

Organism and maintenance. Our laboratory strain of $B$. subtilis $168(\mathrm{CH} 724)$ is a prototrophic derivative of that used by Coley et al. (1975). Stock cultures were stored at $-20^{\circ} \mathrm{C}$ in TYE broth containing $15 \%(\mathrm{v} / \mathrm{v})$ glycerol, and maintained for short periods on TYE medium solidified with $1.5 \%(\mathrm{w} / \mathrm{v})$ agar (Difco). TYE medium contained $\left(1^{-1}\right) 16 \mathrm{~g}$ Bacto-tryptone (Difco), $10 \mathrm{~g}$ yeast extract (Difco) and $5 \mathrm{~g} \mathrm{NaCl}$. Chemostat cultures were always initiated from the glycerol-preserved stock.

Chemostat culture. Continuous cultures, under magnesium or phosphate limitation, were grown in a chemostat (L H Engineering) (Lang et al, 1982) with automatic pH control (by addition of aqueous $3 \mathrm{M}-\mathrm{NH}_{4} \mathrm{OH}$ ) and 
antifoam addition (Dow Corning X2-3240). The total culture volume was 1 litre and the dilution rate $0 \cdot 2 \mathrm{~h}^{-1}$. Temperature was maintained at $37^{\circ} \mathrm{C}$ and $\mathrm{pH}$ at 7.0 . The culture was aerated at $21 \mathrm{~min}^{-1}$ and stirred at 750 r.p.m.

The defined medium was that described by Lang et al. (1982). Phosphate-limiting medium contained $0 \cdot 25 \mathrm{~mm}$ inorganic phosphate and magnesium-limiting medium $5 \mathrm{~mm}$ inorganic phosphate; the magnesium concentration for both limitations was $75 \mu \mathrm{M}$ and the carbon source was glycerol $(30 \mathrm{~mm})$, autoclaved in the medium. Tryptophan, separately filter-sterilized, was added to $1 \mathrm{~mm}$.

Continuous cultures were initiated by addition of $50 \mathrm{ml}$ of a late-exponential culture in TYE broth to $950 \mathrm{ml}$ magnesium-limiting medium in the chemostat. After culturing for $12 \mathrm{~h}$ without dilution, medium flow was commenced and continued for at least 10 generation times to ensure steady state. Culture density was monitored by measurement of optical density in samples diluted to give readings in the range of $0.2-0.6$ at $600 \mathrm{~nm}$. The dilution rate was calculated from the measured medium flow rate and the volume of culture in the vessel, measured at the end of the experiment.

Collection and treatment of samples from the chemostat culture. In balanced growth and during the changes between limitations samples $(12 \mathrm{ml})$ were collected from the overflow of the chemostat into a vessel at $0{ }^{\circ} \mathrm{C}$. A portion $(1 \mathrm{ml})$ of each sample was immediately centrifuged at $10000 \mathrm{~g}$ for $2 \mathrm{~min}$ and the supernatant stored at $-20^{\circ} \mathrm{C}$ for subsequent estimation of inorganic phosphorus. A portion $(10 \mathrm{ml})$ of each sample was also added to $0.43 \mathrm{ml} \mathrm{25 \%} \%(\mathrm{v} / \mathrm{v})$ glutaraldehyde (Polaron) and incubated with gentle shaking at $37^{\circ} \mathrm{C}$ for $2 \mathrm{~h}$. Glutaraldehydefixed bacteria were recovered by centrifugation at $15000 \mathrm{~g}$ for $10 \mathrm{~min}$ at room temperature and suspended in $1 \mathrm{ml}$ $1 \%(\mathrm{v} / \mathrm{v})$ glutaraldehyde at room temperature. These samples were embedded and dehydrated for electron microscopy within $36 \mathrm{~h}$ of collection.

Electron microscopy. Fixed bacteria were recovered from $1 \%$ glutaraldehyde by brief centrifugation ( $1400 \mathrm{~g}$ for 5 $\mathrm{min})$ and taken up into agar $(2 \%, \mathrm{w} / \mathrm{v}$, in water) blocks as described previously (Hobot et al., 1984). Samples were completely dehydrated in a graded series of increasing ethanol concentration followed by infiltration and embedding in the acrylic resin LR White (London Resin Co.) following the procedure of Newman \& Hobot (1987). However, an extra step of an overnight infiltration with pure resin, then two further changes of 30 min were added. Samples were polymerized chemically at $0^{\circ} \mathrm{C}$ for $24 \mathrm{~h}$, then hardened for $2 \mathrm{~h}$ at $50^{\circ} \mathrm{C}$ (Newman \& Hobot, 1987).

Thin sections were cut on an LKB Ultramicrotome III with glass knives and stained with $2 \%(w / v)$ or $0 \cdot 2 \%$ aqueous uranyl acetate for $1 \mathrm{~min}$ with or without subsequent treatment with the lead acetate of Millonig (1961) for 0.5-1 min. Sections were examined in a Philips 300 electron microscope operating at $80 \mathrm{kV}$.

Relative densities of staining of different parts of the cell wall were measured on electron micrograph prints using the Gemini image analysis system (Joyce Loebl).

Phosphate estimation. Total phosphorus in culture supernatants was measured by the method of Chen et al. (1956), after digestion of the samples with ethanolic $\mathrm{Mg}\left(\mathrm{NO}_{3}\right)_{2}$ (Ames, 1966).

Uronic acid estimation. Glucuronic acid in cell wall TUs was measured by the method of Blumenkrantz \& AsboeHansen (1973).

Metal binding to cell walls. Cell walls from B. subtilis 168 grown in chemostat culture under phosphate limitation (feed $P_{i}$ concentration $0.35 \mathrm{mM}$ ) and under magnesium limitation (feed $P_{i}$ concentration $5 \mathrm{mM}$ ) were prepared as described by Lang et al. (1982). Samples $(1 \mathrm{mg}$ ) were treated with glutaraldehyde, uranyl acetate and alkaline lead acetate following the protocol described for staining thin sections for electron microscopy. Treated walls were washed with distilled water and the absorbed metals were then extracted into a mixture of concentrated nitric acid $60 \%(\mathrm{w} / \mathrm{v})$ perchloric acid $(6: 1, \mathrm{v} / \mathrm{v})$ under reflux for $20 \mathrm{~min}$. Metal concentrations were measured in the extract by atomic absorption spectrometry for lead (Pye Unicam SP9 atomic absorption spectrometer), or by the arsenazo III colorimetric method for uranium (Zosim et al., 1983).

Chemicals. Chemicals were AnalaR grade (BDH) unless otherwise stated.

\section{RESULTS}

\section{Differential staining of anionic polymers in the B. subtilis cell wall}

Cells of B. subtilis 168 grown in chemostat culture under phosphate-replete conditions (magnesium limitation) synthesize and incorporate TA into their walls. Electron micrographs of thin sections of such cells show the wall and associated cytoplasmic membrane, together referred to as the cell envelope, to contain bands of markedly different electron density (Figs $1 a$ and $2 a$ ). Immediately outside the electron-translucent inner layer of the cytoplasmic membrane, seen only rarely as a double-track in this type of preparation (Hobot et al., 1984), is a very electronopaque band, the 'A' layer (Fig. 2a), which appears to consist of the outer leaf of the cytoplasmic membrane and a layer possibly of an anionic polymer like membrane TA (see Discussion). 


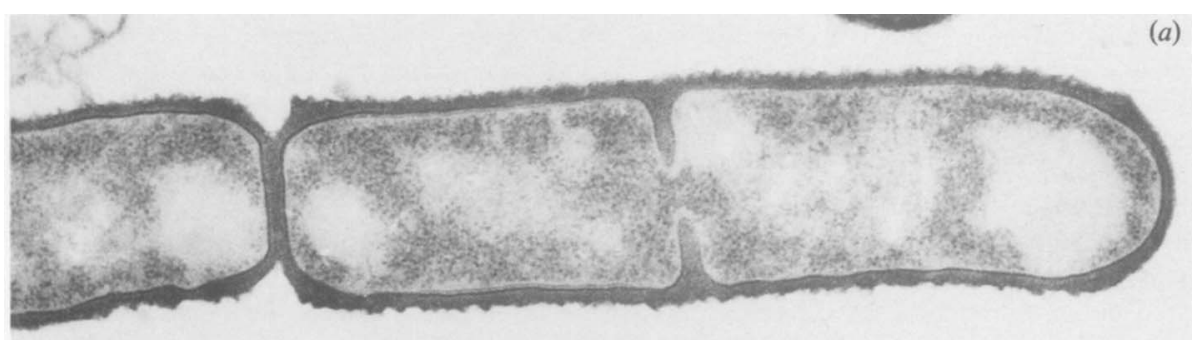

(b)

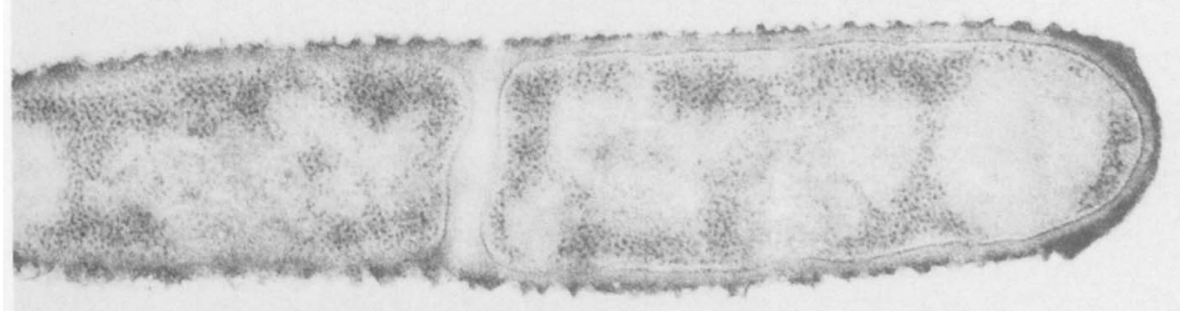

(c)
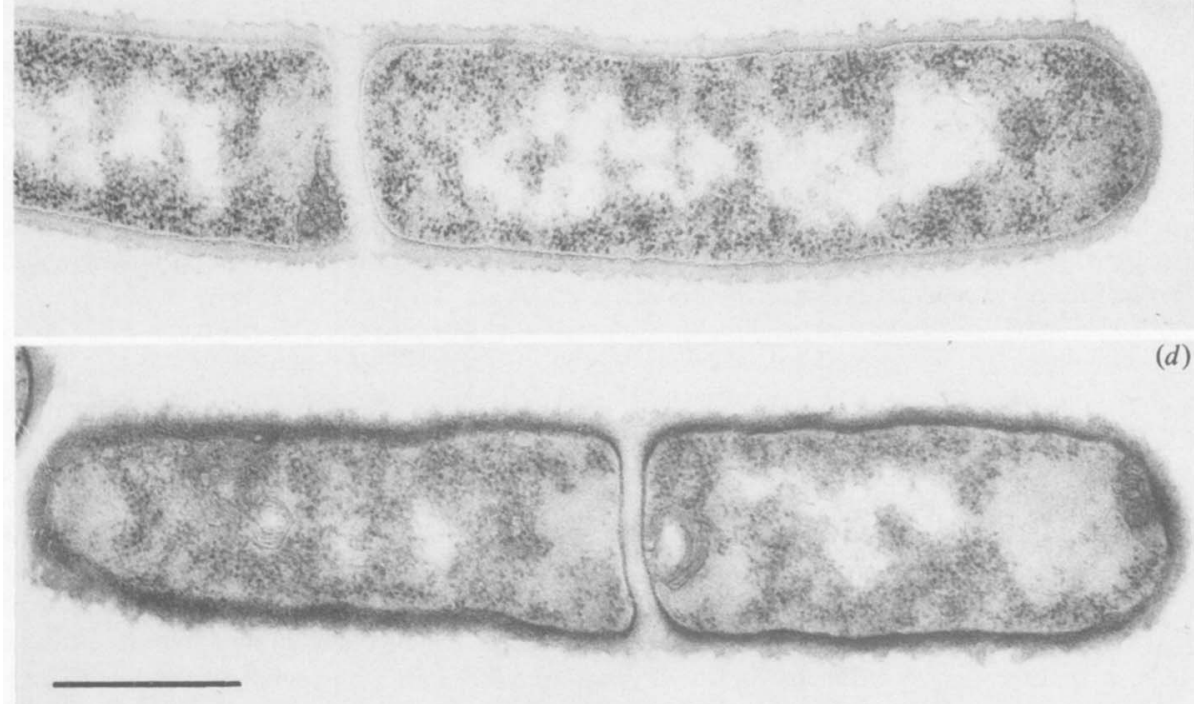

Fig. 1. Deposition of new cell envelope material in B. subtilis 168 during transition from magnesium to phosphate limitation $(a-c)$ and during transition from phosphate to magnesium limitation $(d)$. Samples were collected $(a) 5 \mathrm{~h},(b) 10 \mathrm{~h},(c) 10 \mathrm{~h}$ and $(d) 1.5 \mathrm{~h}$ after changeover. Bar marker, $0.5 \mu \mathrm{m}$.

Towards the outside of the cell at least two other layers are discernible: a thinner less electronopaque inner ' $B$ ' layer and an outer thick electron-opaque but heterogeneous ' $C$ ' layer. The ragged appearance of the latter layer is presumably due to the activity of autolysins which are responsible for cleaving material from the outer surfaces of the cylindrical regions of the cell wall (Frehel et al., 1971). It is notable that the poles are comparatively smooth, suggesting a reduced level of autolytic activity or a different mechanism of wall growth and turnover (see, for example, Fig. $1 a$ ).

Fig. 3 shows the rate of depletion of phosphorus from the culture medium during the period following the change to the phosphate-limiting medium. The phosphate concentration falls to 
(a)

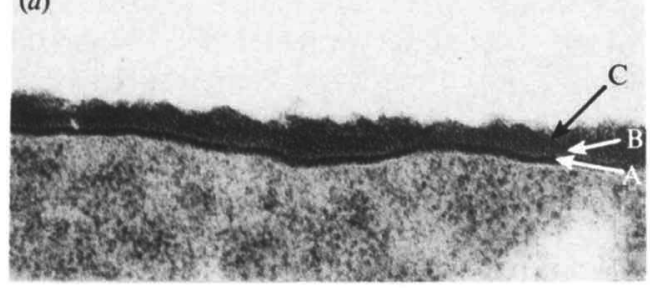

(b)

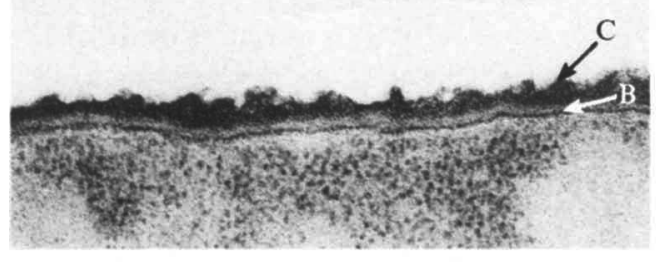

(c)

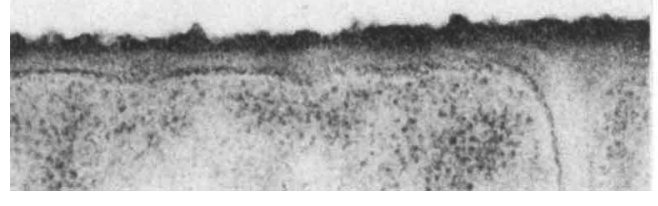

(d)

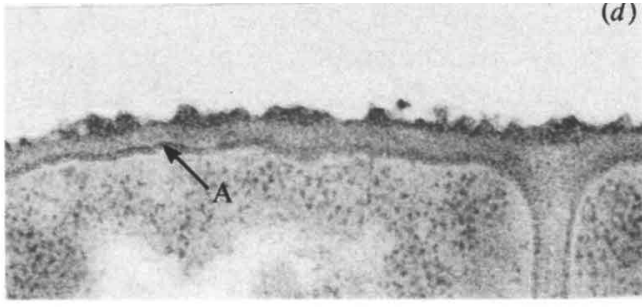

(e)

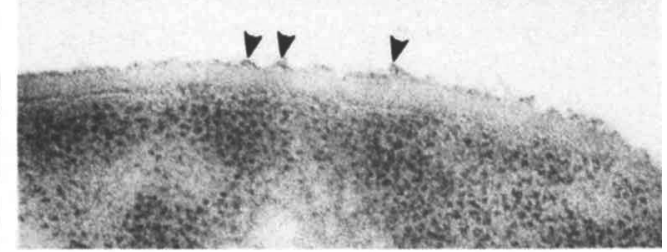

$(f)$

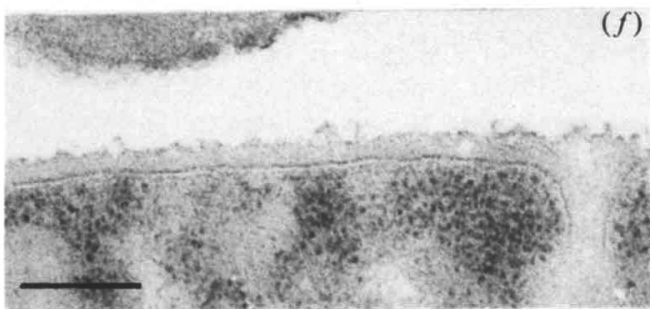

Fig. 2. Deposition of new cell envelope material in B. subtilis 168 during transition from magnesium to phosphate limitation. Bacteria were equilibrated under magnesium limitation at a dilution rate of $0.2 \mathrm{~h}^{-1}$ and the inflowing medium was changed to effect phosphate limitation. Samples were collected (a) $5 \mathrm{~h},(b) 8.5 \mathrm{~h},(c) 10 \mathrm{~h},(d) 10 \mathrm{~h},(e) 11.5 \mathrm{~h}$ and $(f) 13 \mathrm{~h}$ after changeover. Bar marker, $0.2 \mu \mathrm{m}$. Layers $\mathrm{A}, \mathrm{B}$ and $\mathrm{C}$, and the feature indicated by the arrowheads, are discussed in the text.

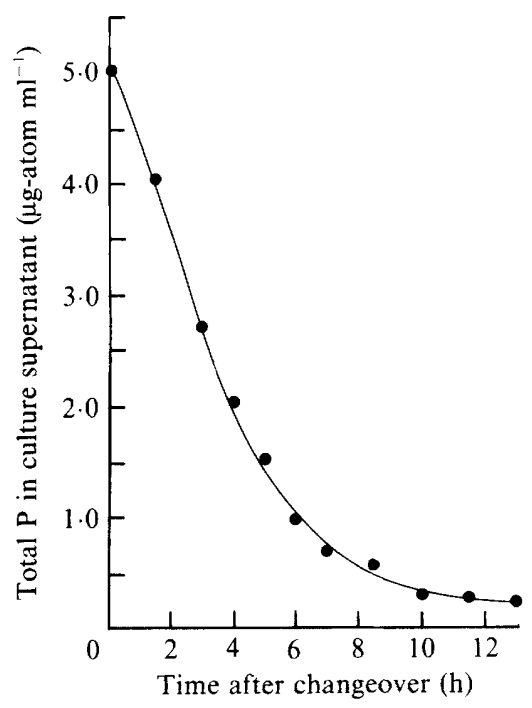

Fig. 3. Total phosphate in the culture during transition from magnesium to phosphate limitation. Bacteria were equilibrated under magnesium limitation at a dilution rate of $0.2 \mathrm{~h}^{-1}$ and the inflowing medium was changed to effect phosphate limitation. 
about $0.65 \mathrm{~mm}$ over a period of $7 \mathrm{~h}$. During this time the rate of TU synthesis is increased and that of TA is decreased. The first changes in cell envelope structure which accompany the transition from phosphate-replete to phosphate-limiting medium are observed between 7 and $8.5 \mathrm{~h}$ after medium changeover (Fig. $2 b$ ). The ' $\mathrm{C}$ ' layer remains electron opaque at the periphery of the cell wall, but appears to become thinner as the electron-translucent region adjacent to the ' $\mathrm{B}$ ' layer expands. In samples taken at $10 \mathrm{~h}$ (Fig. $2 c$ ) there is even less of the electron-opaque ' $\mathrm{C}$ ' layer as the inner wall layer increases in thickness and the ' $A$ ' layer begins to reduce in electron density. In samples taken at $10 \mathrm{~h}$ (Figs $1 b$ and $2 d$ ) more than half of the electron-opaque ' $\mathrm{C}$ ' layer has disappeared and areas of the ragged, outermost part of this layer are starting to be replaced by less densely staining material so that in places sections of the wall consist only of less dense material. In samples taken at $11.5 \mathrm{~h}$ discrete patches of darkly staining material are present and these are found only at the very outer edge of the cell wall (Fig. $2 e$, arrowed). At $13 \mathrm{~h}$ darkly staining material has been completely removed from the cylinder of the cells (Fig. $2 f$ ). At that time the electron density of the ' $A$ ' layer is much reduced, as compared to the densely stained material observed under phosphate-replete conditions (Fig. 2a), and has a doubletracked appearance (see Discussion).

Cells grown for about 5 generation times under conditions of phosphate limitation have weakly staining walls with no division of the wall into 'B' and ' $\mathrm{C}$ ' layers (Fig. $4 a$ ). The 'A' layer has a double-tracked appearance. One hour after changing over to phosphate-replete (magnesium-limiting) medium, the innermost ' $A$ ' layer is seen to increase in electron opacity (Fig. $4 b$ ), and at $1.5 \mathrm{~h}$ its double-tracked appearance is lost (Fig. $4 c$ ). At the latter time, however, a layer of increased electron opacity is observed in the inner part of the wall just outside the ' $A$ ' layer (Fig. $4 c$, arrowed). The outermost, ragged region of the wall remains weakly stained (Figs $1 d$ and $4 c$ ) and the inner electron-opaque layer increases in width (Fig. $4 d$ ). At $2.5 \mathrm{~h}$ the ' $\mathrm{C}$ ' layer is uniformly electron dense except for patches of lightly stained material at the outer surface of the cell (Fig. $4 e$, arrowed), but by this time most of the walls have completely regained their multilayered appearance (compare Fig. $4 f$ with Fig. $2 a$ ). These patches of wall material are occasionally seen for up to $3 \mathrm{~h}$ after changeover to phosphate-replete conditions (not shown).

Previous experiments have shown that when $B$. subtilis growing under phosphate-replete conditions is changed to phosphate-limited conditions, TA synthesis stops and this polymer is replaced by newly synthesized TU (Ellwood \& Tempest, 1969). The reverse occurs during transition in the opposite direction. We interpret the electron microscope results as showing differential staining of these anionic wall polymers and their location in the wall.

\section{Quantitative analysis of the staining procedure for electron microscopy}

Results presented above suggest that a larger amount of one or both of the heavy metal ions used in the staining procedure, lead or uranium, was bound to TA than to TU. The stoichiometry of lead and uranium binding to isolated cell walls stained by the electron microscopy procedure was measured using walls containing TA or TU as predominant anionic polymer, before and after treatment with glutaraldehyde. Table 1 shows the amount of lead and uranium bound by the walls. The only significant difference in metal content between the two types of wall was between the amounts of uranium present, TA-containing walls binding 1.7 times as much uranium as the TU-containing ones. Treatment of the walls with uranyl acetate alone, under the same conditions, led to the same difference in uranium content; the subsequent treatment with lead acetate slightly reduced the amount of uranium bound. Thin sections treated with $0.2 \%$ instead of $2 \%$ uranyl acetate showed the same differential staining (compare Fig. $5 a$ with Fig. $2 b$ ). The metal-binding results suggested that staining with uranyl acetate alone should provide as much contrast between the different kinds of wall material as obtained with uranium plus lead, though the overall density would be reduced. This was confirmed (compare Fig. $5 b$ with Fig. $2 d$ ).

The relative densities of stain (uranium plus lead) in strongly stained and weakly stained layers within the thickness of a single cell wall section (see for example Figs. $2 b$ and $4 b$ ) were measured in micrographs of single cells using a video-scanning image analysis system. In a sample in transition from phosphate to magnesium limitation, the ratio of optical densities of 
(a)
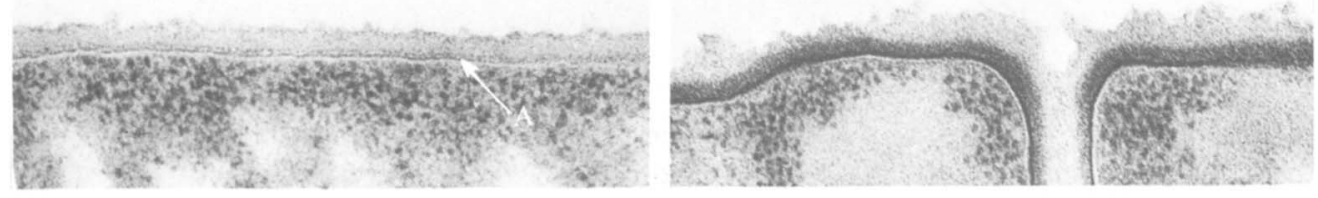

(b)

(e)
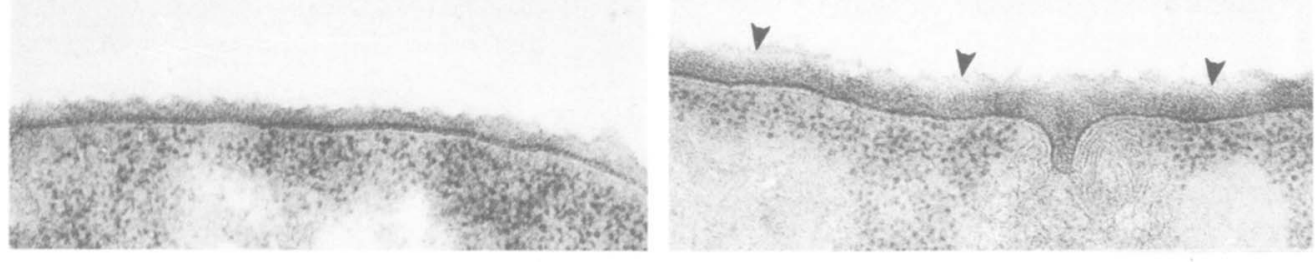

(c)
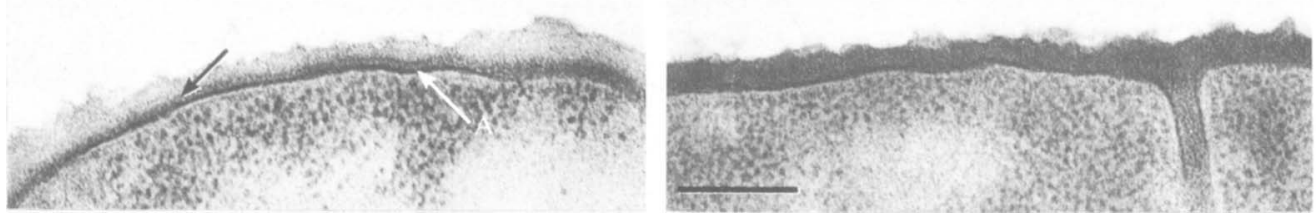

Fig. 4. Deposition of new cell envelope material in $B$. subtilis 168 during transition from phosphate to magnesium limitation. Bacteria were equilibrated under phosphate limitation at a dilution rate of $0.2 \mathrm{~h}^{-1}$ and the inflowing medium was changed to effect magnesium limitation. Samples were collected (a) $0 \mathrm{~h},(b) 1 \mathrm{~h},(c) 1.5 \mathrm{~h},(d) 1.5 \mathrm{~h},(e) 2.5 \mathrm{~h}$ and $(f) 2.5 \mathrm{~h}$ after changeover. Bar marker, $0.2 \mu \mathrm{m}$. Layer A, and the feature indicated by the arrowheads, are discussed in the text.
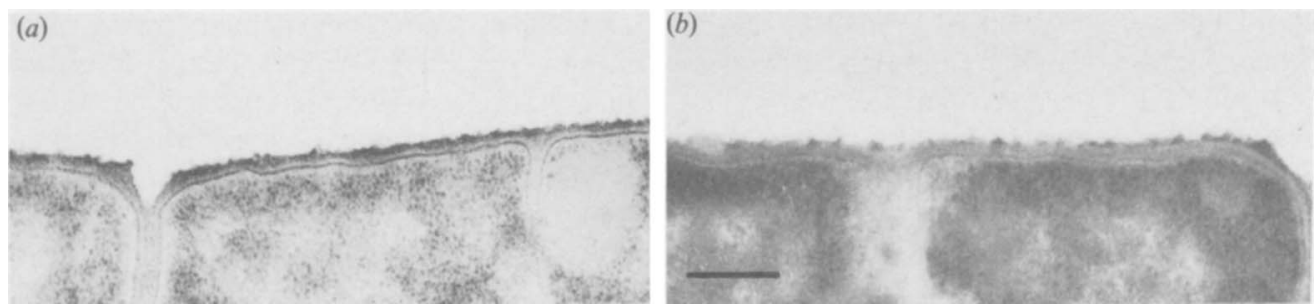

Fig. 5. Deposition of new cell envelope material in $B$. subtilis 168 during transition from magnesium to phosphate limitation. (a) Sample collected after $8.5 \mathrm{~h}$ and stained with $0.2 \%$ uranyl acetate and lead acetate; (b) sample collected after $10 \mathrm{~h}$ and stained with $2 \%(\mathrm{w} / \mathrm{v})$ uranyl acetate in the absence of lead acetate. Bar marker, $0 \cdot 25 \mu \mathrm{m}$.

\section{Table 1. Quantification of metal binding to cell walls in the staining procedure}

The figures are means of triplicate measurements of samples from duplicate experiments. Measurements varied from the mean by less than $1 \%$, and the results of duplicate experiments differed from the mean by less than $2 \%$.

$\begin{array}{lccccc}\text { Staining procedure } & \overbrace{\text { TA-containing wall }}^{\text {Uranium }} & \text { Lead } & \overbrace{\text { Uranium }}^{\text {TU-containing wall }} & \text { Lead } \\ \text { Sout glutaraldehyde fixation } & 490 & 516 & 290 & 497 \\ \text { glutaraldehyde fixation } & 493 & 529 & 304 & 463\end{array}$

Without glutaraldehyde fixation With glutaraldehyde fixation
493 
the two types of wall, at a site of contact between the two within the cylindrical part of the wall, was 1.9 .

\section{DISCUSSION}

Wall material that contains TA can be distinguished from wall material that contains TU by direct electron microscopic examination of sections of chemostat-grown and glutaraldehydefixed cells of $B$. subtilis, embedded in an acrylic resin and stained with uranyl and lead acetate. The discrimination is due to a difference in uranium uptake, and the difference in staining intensity, measured on the electron micrographs, is similar to the difference in the amounts of uranium bound by wall samples containing the different anionic polymers. This affords a new and more direct technique for examining the location of old and new material throughout the entire thickness of walls of bacilli undergoing transitions between growth conditions that change the anionic polymer being synthesized.

The ability of walls of Gram-positive bacteria to bind cations is well documented (Hancock, 1986) and is due primarily to the anionic polymers TA and TU. Under some conditions (Heckels et al., 1977) metals are bound equally well by walls containing either of the anionic polymers but, as shown here, under the conditions used for electron microscopy staining, uranium cations are bound more extensively by walls of $B$. subtilis that contain TA. Isolated cell walls fixed and stained by the procedure used for thin sections bound $1 \cdot 2-1 \cdot 3 \mu \mathrm{g}$-atoms uranium per microequivalent anionic group (TA walls) or $0.8 \mu \mathrm{g}$-atoms uranium per microequivalent anionic group (TU walls). No attempt was made to achieve equilibrium binding and there was no evidence of the substantial precipitation of insoluble uranium hydroxides that occurs on prolonged exposure of the cell walls to uranyl salts (Beveridge, 1978). Substantial binding of lead, which must have occupied the same and/or additional, unknown, sites in the walls, was unnecessary for the differential staining of TA- and TU-containing walls (see Fig. $5 b$ ).

We examined the cell wall of $B$. subtilis 168 undergoing transitions between phosphate limitation, when TU is the major anionic polymer present, and magnesium limitation, when TA is present instead. Under the particular growth conditions used here, walls of the phosphatelimited bacteria contain $1.44 \mathrm{mmol}$ TU carboxyl and $0.06 \mathrm{mmol}$ TA phosphate per gram of wall whereas those of magnesium-limited bacteria contain $1.61 \mathrm{mmol}$ TA phosphate and less than $0.01 \mathrm{mmol}$ TU carboxyl per gram of wall. No information is available on the differences in contents of membrane TA and phospholipids in the bacteria under the particular conditions studied here. However, phosphate-limited $B$. licheniformis was shown to contain only one-tenth as much membrane TA (Button et al., 1975) and only half as much phospholipid (Minnikin et al., 1972) as do the bacteria grown under conditions where phosphate is freely available.

Changes in staining are seen throughout the envelope during the growth transitions and appear to involve the outer leaf of the cytoplasmic membrane as well as the cell wall. Magnesium-limited bacteria show a narrow, intensely staining layer (the ' $A$ ' layer) which shows changes in staining intensity that appear independent of the changes in the overlying wall layers. For example, in bacteria undergoing transition to phosphate limitation, less densely staining material becomes incorporated into the inner ' $B$ ' wall layer before any change is seen in the staining of the innermost intensely staining ' $A$ ' layer. The sharply defined appearance of the ' $A$ ' layer and its possible relation with the outer leaflet of the cytoplasmic membrane, together with the consideration that new material is seen in outer wall layers before it is seen in the 'A' layer, suggests that this layer is associated with membrane rather than being an innermost layer of the wall. Although direct experimental evidence is not available the chemical similarity of membrane and wall TAs suggests that they will have similar uranium binding properties and it seems possible that the intense staining of the ' $A$ ' layer is due to membrane TA. The change of the 'A' layer to a less electron-opaque appearance in phosphate-limited bacilli is consistent with its diminished content of membrane TA (Button et al., 1975).

During transition from limiting to excess phosphate, walls acquire densely staining material at the inner region and the amount of this material increases as the outer, less intensely staining 
material decreases. During transition in the reverse direction walls acquire lightly staining material and the intensely stained material becomes increasingly confined to only the outermost region of the wall. These results show that differently staining material incorporated following a change in growth conditions appears first in the inner region of the wall while the existing, or older, material is gradually displaced so that it is found only in the outer fringes of the wall. This occurs both during transition to phosphate limitation, when the new material (TUpeptidoglycan complex) is that which stains less intensely and during transition from phosphate limitation, when the new material (TA-peptidoglycan complex) is that which stains more intensely. Our micrographs provide the clearest evidence to date that new wall is incorporated at the inner surface of the cylindrical wall in $B$. subtilis and moves outward during growth, and corroborate the conclusions of Archibald \& Coapes (1976) and Pooley $(1976 a, b)$. In the accompanying paper (Clarke-Sturman et al., 1989), the same differential staining technique is used to investigate the incorporation of new material into polar caps.

As well as confirming the inside-to-outside direction of cylindrical wall assembly, the micrographs provide information relating to the existence of growth zones. The original evidence for specific growth zones came from work using fluorescent antibody techniques. The interpretation of these results was based on the premise, subsequently shown to be incorrect (Archibald \& Coapes, 1976), that new wall material is detectable immediately at the bacterial surface. More recently Schlaeppi et al. (1982) have concluded that their autoradiographic experiments show that the wall in $B$. subtilis is incorporated in a small number of specific zones whereas Mobley et al. (1984), partly on the basis of similar autoradiographic results, have concluded that incorporation takes place at many sites. In both of these studies conclusions have been based on the distribution of residual radiolabelled wall several generation times after its incorporation. That approach is questionable firstly because an increasingly large proportion of the total radioactivity present in samples collected after a chase may be due to protein rather than to cell wall (Clarke-Sturman \& Archibald, 1982; Mobley et al., 1984) and secondly (Anderson et al., 1978) because the relation between the sites at which material is incorporated into the wall and those to which it moves later is not known. This latter reservation applies equally to our observations (Anderson et al., 1978) on the locations at which phages bind to whole cells of $B$. subtilis following transition from phosphate limitation and to the similar observations made by Mobley et al. (1984) on the locations at which fluorescent concanavalin A bound to mutants following transition to and from conditions permissive for synthesis of $\alpha$-glucosylated TA.

Though experimental and theoretical studies of wall assembly in bacilli have been recently pursued (see Koch \& Doyle, 1986; Doyle \& Koch, 1987), no direct evidence relating to the location or number of sites at which new material is incorporated into the inner wall surface has appeared since Archibald (1976) showed that phage SP50 bound along the inner surface of walls isolated from bacteria collected during release of phosphate limitation. As mentioned above, the phage technique does not discriminate between regions of the wall which have incorporated substantial amounts of new material and those in which much smaller amounts are present, so specific 'growth zones' could be obscured by a secondary incorporation related to wall turnover.

The selective staining procedure described here avoids that difficulty and shows the relative proportions of different materials as well as their locations. The micrographs show that the envelope contains bands that stain at markedly different intensities, particularly in bacteria grown under phosphate-replete conditions.

During transition to phosphate limitation changes are seen in all of the envelope layers. In all cases the changes appear uniformly along the length of the wall cylinder (Fig. 1) and there is no indication of any localized zone of thicker material. Changes seen in envelope layers during transition from phosphate limitation mirror those seen in the opposite direction and again no zones are seen where the newer or older wall material is of differing thickness.

We conclude from these observations that new material is incorporated uniformly along the length of the wall cylinder. As mentioned previously (Anderson et al., 1978) this does not necessarily imply a uniform distribution of synthetic sites in the membrane, and it does not exclude the possibility that there might be a limited number of such sites. Their detection would 
depend, however, upon how much of the total wall material must be present as 'new ' wall of altered composition before it can be visualized by the present technique. Our results could therefore be consistent with suggestions made by Mendelson (Mendelson, 1976, 1985; Mendelson et al., 1984) that wall is laid down from a limited number of synthetic sites that move round the membrane. Provided that such sites fully traverse the wall cylinder in the time taken to incorporate the minimum of wall material necessary for visualization, a markedly asymmetric mode of incorporation could nevertheless give an apparently uniform distribution. While such asymmetric incorporation cannot be demonstrated directly, at least by currently available techniques, Mendelson's studies clearly show anisotropy in the wall (Mendelson et al., 1984) that must reflect some aspects of the structure, arrangement and assembly that have so far been exposed only in studies of macrofibre formation.

This work was partly funded by the Medical Research Council. T.M. is in receipt of a Studentship from the Algerian Ministry of Education. We thank Dr L. A. Harrison for measurements of lead and acknowledge the excellent assistance of Kevin Glassey and Clive Mellstrom.

\section{REFERENCES}

AMEs, B. N. (1966). Assay of inorganic phosphate, total phosphate and phosphatases. Methods in Enzymo$\log y 8,115-118$.

Anderson, A. J., Green, R. S., Sturman, A. J. \& ARCHIBALD, A. R. (1978). Cell wall assembly in Bacillus subtilis : location of wall material incorporated during pulsed release of phosphate limitation, its accessibility to bacteriophages and concanavalin $A$, and its susceptibility to turnover. Journal of Bacteriology 136, 886-899.

ARCHIBALD, A. R. (1976). Cell wall assembly in Bacillus subtilis: development of bacteriophage-binding properties as a result of the pulsed incorporation of teichoic acid. Journal of Bacteriology 127, 956-960.

ARChibald, A. R. \& CoAPES, H. E. (1976). Bacteriophage SP50 as a marker for cell wall growth in Bacillus subtilis. Journal of Bacteriology 125, 11951206.

BEVERIDGE, T. J. (1978). The response of cell walls of Bacillus subtilis to metals and to electron-microscopic stains. Canadian Journal of Microbiology 24, 89-104.

Blumenkrantz, N. \& Asboe-Hansen, G. (1973). New method for quantitative determination of uronic acids. Analytical Biochemistry 53, 484-489.

Button, D., Choudry, M. K. \& Hemmings, N. L. (1975). Lipoteichoic acid from Bacillus licheniformis and one of its mutants. Proceedings of the Society for General Microbiology 2, 45.

Chen, P. S., Toribara, T. Y. \& Warner, H. (1956). Microdetermination of phosphorus. Analytical Chemistry 28, 1756-1758.

Chung, K. L., Hawirko, R. Z. \& Isaac, P. K. (1964). Cell wall replication. 1. Cell wall growth of Bacillus cereus and Bacillus megaterium. Canadian Journal of Microbiology 10, 43-48.

Clarke-Sturman, A. J. \& Archibald, A. R. (1982). Cell wall turnover in phosphate and potassium limited cultures of Bacillus subtilis W23. Archives of Microbiology 131, 375-379.

Clarke-Sturman, A. J., Archibald, A. R., HanCOCK, I. C., HaRwOOD, C. R., MERAD, T. \& Hobot, J. A. (1989). Cell wall assembly in Bacillus subtilis: partial conservation of polar wall material and the effect of conditions on the pattern of incorporation of new material at the polar caps. Journal of General Microbiology 135, 657-665.

Coley, J., Duckworth, M. \& Baddiley, J. (1975). Extraction and purification of lipoteichoic acids from Gram-positive bacteria. Carbohydrate Research 40, 41-50.

Doyle, R. J. \& KoCH, A. L. (1987). The function of autolysins in division and growth of Bacillus subtilis. $C R C$ Critical Reviews in Microbiology 15, 169 221.

Ellwood, D. C. \& Tempest, D. W. (1969). Control of teichoic acid and teichuronic acid biosynthesis in chemostat cultures of Bacillus subtilis var. niger. Biochemical Journal 111, 1-5.

Fan, D. P., BeCKMAN, B. E. \& GaRdner-Eckstrom, H. L. (1975). Mode of cell wall synthesis in Grampositive bacilli. Journal of Bacteriology 123, 1157 1162.

Frehel, C., Beaufils, A.-M. \& Ryter, A. (1971). Étude au microscope électronique de la croissance de la paroi chez $B$. subtilis et $B$. megaterium. Annales de l'Institut Pasteur 121, 139-148.

Givan, A. L., Glassey, K., LanG, W. K., Anderson, A. J. \& ARChIBALD, A. R. (1982). Relation between wall teichoic acid content of Bacillus subtilis and efficiency of adsorption of bacteriophages SP50 and Ф25. Archives of Microbiology 133, 318-322.

Hancock, I. C. (1986). The use of Gram-positive bacteria for the removal of metals from aqueous solutions. In Trace Metal Removal from Aqueous Solution, Royal Society of Chemistry Special Publication no. 61, pp. 25-43. Edited by R. Thompson. London: Royal Society of Chemistry.

Heckels, J. E., LamberT, P. A. \& Baddiley, J. (1977). Binding of magnesium ions to cell walls of Bacillus subtilis W23 containing teichoic acid or teichuronic acid. Biochemical Journal 162, 359-365.

Новот, J. A., Carlemalm, E., Villiger, W. \& Kellenberger, E. (1984). Periplasmic gel: new concept resulting from the reinvestigation of bacterial cell ultrastructure by new methods. Journal of Bacteriology 160, 143-153.

Hughes, R. C. \& Stokes, E. (1971). Cell wall growth in 
Bacillus licheniformis followed by immunofluorescence with mucopeptide-specific antiserum. Journal of Bacteriology 106, 694-696.

JaCoB, F., Brenner, S. \& Cuzin, F. (1963). On the regulation of DNA replication in bacteria. Cold Spring Harbor Symposium on Quantitative Biology 28 , 329-348.

KoCH, A. L. \& DoyLE, R. J. (1986). Growth strategy for the Gram-positive rod. FEMS Microbiology Reviews 32, 247-254.

LANG, W. K., Glassey, K. \& ARChibald, A. R. (1982). Influence of phosphate supply on the teichoic acid and teichuronic acid content of walls of Bacillus subtilis. Journal of Bacteriology 151, 367-375.

MaucK, J. \& Glaser, L. (1972). On the mode of in vivo assembly of cell wall of Bacillus subtilis. Journal of Biological Chemistry 247, 1180-1187.

Mauck, J., Chan, L. \& Glaser, L. (1971). Turnover of the cell wall of Gram positive bacteria. Journal of Biological Chemistry 246, 1820-1827.

Mendelson, N. H. (1976). Helical growth of Bacillus subtilis: a new model for cell growth. Proceedings of the National Academy of Sciences of the United States of America 73, 1740-1744.

Mendelson, N. H. (1985). A model of bacterial DNA segregation based upon helical geography. Journal of Theoretical Biology 112, 25-39.

Mendelson, N. H., Favre, D. \& Thwaites, J. J. (1984). Twisted states of Bacillus subtilis macrofibers reflect structural states of the cell wall. Proceedings of the National Academy of Sciences of the United States of America 81, 3562-3566.

Millonig, G. (1961). A modified procedure for lead staining of thin sections. Journal of Biophysical and Biochemical Cytology 11, 736-739.

Minnikin, D. E., AbDUlRahimzadeh, H. \& Baddiley, J. (1972). Variation of polar lipid composition of Bacillus subtilis Marburg with different growth conditions. FEBS Letters 27, 16-18.

Mobley, H. L. T., KoCH, A. L., DOYle, R. J. \& STREIPS, U. N. (1984). Insertion and fate of the cell wall in Bacillus subtilis. Journal of Bacteriology $\mathbf{1 5 8}$, 169-179.

Newman, G. R. \& Hobot, J. A. (1987). Modern acrylics for post-embedding immunostaining techniques. Journal of Histochemistry and Cytochemistry 35, $971-981$.

Pooley, H. M. (1976a). Turnover and spreading during surface growth of Bacillus subtilis. Journal of Bacteriology 125, 1127-1138.

Pooley, H. M. (1976b). Layered insertion according to age within the cell wall of Bacillus subtilis. Journal of Bacteriology 125, 1139-1147.

Schlaeppi, J. M., Pooley, H. M. \& Karamata, D. (1982). Identification of cell wall subunits in Bacillus subtilis and their segregation during growth. Journal of Bacteriology 149, 329-337.

Zosim, Z., Gutnick, D. \& Rosenberg, F. (1983). Uranium binding by emulsan and emulsan sols. Biotechnical Biology 25, 1725-1735. 